\title{
Alternative methodology for chitin-hydroxyapatite composites using ionic liquids and supercritical fluid technology
}

Journal of Bioactive and Compatible Polymers 28(5) $48 \mid-491$

(c) The Author(s) 2013

Reprints and permissions: sagepub.co.uk/journalsPermissions.nav DOI: I0.1I77/08839|I5I350I595 jbc.sagepub.com @SAGE

\section{Simone S Silva ${ }^{1,2}$, Ana Rita C Duarte ${ }^{1,2}$, Joaquim M Oliveira ${ }^{1,2}$, João F Mano',2 and Rui L Reis ${ }^{1,2}$}

\begin{abstract}
An alternative, green method was used to develop chitin-based biocomposite (ChHA) materials by an integrated strategy using ionic liquids, supercritical fluid drying, and salt leaching. ChHA matrices were produced by dissolving chitin in I-butyl-methylimidazolium acetate along with salt and/or hydroxyapatite particles and then subsequent drying. The ChHA composite formed had a heterogeneous porous microstructure with $65 \%-85 \%$ porosity and pore sizes in the range of 100-300 $\mu \mathrm{m}$. The hydroxyapatite was found to be well distributed within the composite structures and had a positive effect in the viability and proliferation of osteoblast-like cells, in vitro. Our findings indicate that these ChHA matrices have potential applications in bone tissue engineering.
\end{abstract}

\section{Keywords}

Composites, chitin, hydroxyapatite, controlled pore sizes, scaffold pores sizing, ionic liquids, salt leaching, supercritical fluid technology

\section{Introduction}

With growing environmental awareness, material scientists have focused their attention on developing alternative routes for the processing of materials using both renewable resources and "green" solvents. Natural-based polymers are sources of sustainable materials due to their availability and

\footnotetext{
13B's Research Group-Biomaterials, Biodegradables and Biomimetics, University of Minho, Headquarters of the European Institute of Excellence on Tissue Engineering and Regenerative Medicine, Guimarães, Portugal 2ICVS/3B's_-PT Government Associate Laboratory, Braga/Guimarães, Portugal
}

\section{Corresponding author:}

Simone S Silva, 3B's Research Group-Biomaterials, Biodegradables and Biomimetics, University of Minho, Headquarters of the European Institute of Excellence on Tissue Engineering and Regenerative Medicine, AvePark, Zona Industrial da Gandra, Caldas das Taipas, 4806-909 Guimarães, Portugal.

Email: simonesilva@dep.uminho.pt 
ecofriendly properties, namely, biocompatibility, nontoxic, and renewable. ${ }^{1-3}$ Chitin has useful biomaterial properties that are associated with the presence of amino groups. However, chitin also has strong inter- and intramolecular hydrogen bonding, which cause difficulty with its solubility and processability. ${ }^{2}$ Several reports on the development of chitin/chitosan-based porous structures for tissue engineering purposes have been made. ${ }^{4-8}$ Chitin/chitosan reinforced with inorganic elements, such as hydroxyapatite (HA) $\left(\mathrm{Ca}_{10}\left(\mathrm{PO}_{4}\right)_{6}(\mathrm{OH})_{2}\right)$, the major inorganic component of natural bone, ${ }^{6}$ has been investigated for periodontal, maxillofacial, and bone tissue engineering applications. ${ }^{6,9-11}$ In those studies, different success levels were achieved using methods such as freeze-drying and salt leaching. For example, freeze-drying methods resulted in chitin scaffolds with low porosity, whereas particle leaching techniques allowed obtaining scaffolds with very large pore distribution ${ }^{4}$ or with relatively low pore interconnectivity. ${ }^{7}$ On the other hand, ionic liquids (ILs), commonly defined as organic salts, ${ }^{12}$ have been used as solvents for chitin, which may broaden its processability, modification, and, consequently, its application. ${ }^{13-18}$ In this work, we develop an alternative methodology for processing chitin-based biocomposite materials combining the processing of chitin in ILs integrated with the use of supercritical fluid technology (SCF) and salt-leaching techniques. Only a few, studies on the processability of chitin/chitosan in ILs can be found in the literature, ${ }^{14,15,19}$ as most of the attention has been given to cellulose dissolution. ${ }^{20-22}$ In this work, chitin-HA composites were produced using 1-butyl-3-methylimidazolium acetate as solvent for chitin combined with SCF and salt leaching. In our previous studies, ${ }^{15}$ micro-nanoporous structures of chitin with very low density and high porosity were produced through dissolution of chitin in 1-butyl-3-methylimidazolium acetate, followed by SCF. Herein, issues concerning structural features, morphology, porosity, crystallinity, and cellular response of the chitin-HA composites were evaluated.

\section{Materials and methods}

\section{Materials}

Chitin from crab shells (Sigma Aldrich, Portugal) was ground (106 $\mu \mathrm{m})$ and stored in plastic bottles. The IL, 1-butyl-3-methylimidazolium acetate ([bmim][Ac]), from Sigma Aldrich was used as received. Carbon dioxide (99.998 mol\%) was supplied by Air Liquide (Portugal). Salt particles (sodium chloride, $\mathrm{NaCl}, 500 \mu \mathrm{m}$ ) were used as the leachable element. HA (106 $\mu \mathrm{m})$ was synthesized in the laboratory following the methodology previously described. ${ }^{9}$ All other chemicals were of reagent grade and used as received.

\section{Chitin biocomposite preparation and molding}

Chitin was dissolved in 1-butyl-3-methylimidazolium acetate ([bmim][Ac]) in concentrations of 1, 2, and $3 \mathrm{wt} \%$. To generate the porous structures of materials, salt particles ( $1 \mathrm{~g}$ ) and HA powder ( $1 \mathrm{~g}$ ) were dispersed into chitin solutions $(10 \mathrm{~mL})$. After homogenization, the solutions were transferred to silicone molds, followed by gelation of the systems through immersion in ethanol. To leach the salt from the structures, they were immersed in water for 4 days with periodic changes of water. Afterward, the structures were submitted to Soxhlet extraction with ethanol for 3 days for IL removal. The samples were then dried by supercritical fluid drying $\left(100 \mathrm{bar}, 40^{\circ} \mathrm{C}, 1 \mathrm{~h}\right)$. Finally, standardized porous composite chitin structures were obtained in a cylindrical form with diameter of $0.31 \mathrm{~cm}$. Chitin samples with polymer concentrations: 1 , 2, and $3 \mathrm{wt} \%$ were named as ChHA1, ChHA2, and ChHA3, respectively. Prior to cell culture studies, ChHA1, ChHA2, and ChHA3 were sterilized under an ethylene oxide atmosphere. The conditions for the sterilization of the materials were as follows: $45^{\circ} \mathrm{C}$ $\pm 3^{\circ} \mathrm{C}, 180 \pm 3 \mathrm{kPa}, 55 \% \pm 10 \% \mathrm{RH}$, and $10 \mathrm{~h}$ of exposure time. 


\section{Characterization}

Fourier transform infrared spectroscopy. The infrared spectra of chitin structures were obtained with a Shimadzu-IR Prestige 21 spectrometer in the spectral region of $4000-650 \mathrm{~cm}^{-1}$ with resolution of $2 \mathrm{~cm}^{-1}$ at 32 scans. The samples were powdered, mixed with $\mathrm{KBr}$, and processed into pellets.

Scanning electron microscopy. The morphology of the samples coated with gold was investigated at $10 \mathrm{kV}$ on a NanoSEM-FEI Nova 200 equipped with an energy-dispersive spectrometer (EDS).

Micro-computed tomography. The microstructure of the scaffolds was evaluated using a highresolution micro-computed tomography ( $\mu$-CT) Skyscan 1072 scanner (Skyscan, Belgium) with a resolution of pixel size of $6.69 \mu \mathrm{m}$ and integration time of $1.9 \mathrm{~s}$. The X-ray source was set at 71 $\mathrm{keV}$ and $140 \mu \mathrm{A}$ and 300 projections were acquired over a rotation range of $180^{\circ}$ with a rotation step of $0.45^{\circ}$. Data sets were reconstructed using standardized cone-beam reconstruction software (NRecon v1.4.3, Skyscan).

The output format for each sample was 300 serial $1024 \times 1024$ bitmap images. A representative data set of 300 slices was segmented into binary images with a dynamic threshold of 38255 (gray values) for analysis of scaffolds architecture (including both polymeric and ceramic components). For the analysis of the ceramic component in the scaffolds, a threshold of 120-255 was used.

The same representative volume of interest (VOI) was analyzed for all the samples. These data sets were used for morphometric analysis (CT Analyser, v1.5.1.5, Skyscan) and to build the threedimensional (3D) models (ANT 3D creator, v2.4, Skyscan).

X-ray diffraction. X-ray diffraction (XRD) patterns were collected on a Bruker AXS D8 Discover diffractometer ( $40 \mathrm{kV}, 40 \mathrm{~mA}$ ) in $\theta / 2 \theta$ scan regime, using Ni-filtered CuK alpha1,2 radiation, step $0.04^{\circ}$, time per step $1 \mathrm{~s}$, and $2 \theta$ range $4^{\circ}-40^{\circ}$.

\section{In vitro cell culture studies}

Cell expansion and culturing. The cell culture studies were performed using a cell suspension of human osteosarcoma cells (SaOS-2 cell line; European Collection of Cell Cultures (ECACC)) at a concentration of $3.3 \times 10^{4}$ cells $/ \mathrm{mL}$. Triplicates were made for each sample. The cell-material constructs $(600 \mu \mathrm{L})$ were incubated at $37^{\circ} \mathrm{C}$ in a humidified $95 \%$ air $/ 5 \% \mathrm{CO}_{2}$ atmosphere and maintained for 2 weeks with medium changes every 2 days. Triplicates were used per each time point and per each different test. After 1, 3, 7, 14, and 21 days of culture, the medium was removed and samples were washed with phosphate-buffered saline (PBS) and processed for 3-(4,5-dimethylthiazol-2-yl)-5-(3-carboxymethoxyphenyl)-2-(4-sulfophenyl)-2H-tetra-zolium (MTS) testing and DNA quantification.

Viability assay. The MTS test ${ }^{14}$ was performed to assess the metabolic activity of SaOs-2 cells in contact with materials along the culture. For this assay, an MTS solution was prepared using a 1:5 ratio of MTS reagent (CellTiter $96 \AA$, Promega, USA) to culture medium containing Dulbecco's modified Eagle's medium (DMEM) without phenol red, 10\% fetal bovine serum (FBS), and $1 \%$ antibiotic/antimycotic (A/B) solution. The cell constructs were incubated with MTS reagent $(600 \mu \mathrm{L})$ for $3 \mathrm{~h}$ at $37^{\circ} \mathrm{C}$. Finally, the optical density (OD) was read at $490 \mathrm{~nm}$ on a multiwall plate microplate reader (Synergy HT, Bio-Tek Instruments, USA). All tests were performed using six replicates. 
DNA quantification. The SaOs-2 cell proliferation onto chitin materials was determined using a fluorimetric double-strand DNA quantification kit (Quant-iT ${ }^{\mathrm{TM}}$ PicoGreen ${ }^{\circledR}$ dsDNA Assay kit, Molecular Probes, Invitrogen, UK). For that, samples collected at 1, 3, 14, and 21 days were transferred into $1.5-\mathrm{mL}$ microtubes and stored at $-80^{\circ} \mathrm{C}$ until they were tested. Prior to dsDNA quantification, constructs were thawed and sonicated for $15 \mathrm{~min}$. Samples and standards (ranging from 0 to $2 \mathrm{mg} / \mathrm{mL}$ ) were prepared and mixed with a PicoGreen solution in a 200:1 ratio and were placed on an opaque 96-well plate. The plate was incubated for $10 \mathrm{~min}$ in the dark, and fluorescence was measured on a microplate reader (Bio-Tek Instruments) with an excitation of 485/20 nm and an emission of 528/20 nm. A standard curve was created, and sample DNA values were read from the standard graph.

Alkaline phosphatase activity. The alkaline phosphatase (ALP) activity was quantified to evaluate the phenotype of SaOs-2 cell constructs. For that, cell-ChHA constructs used for DNA quantification assay were also used to determine ALP levels. To each well of a 96-well plate were added 20 $\mu \mathrm{L}$ of sample and $60 \mu \mathrm{L}$ of substrate solution: $0.2 \%(\mathrm{w} / \mathrm{v}) \mathrm{p}$-nitrophenyl (pNP) phosphate (Sigma, USA) in a substrate buffer $1 \mathrm{M}$ diethanolamine $\mathrm{HCl}$ (Merck, Germany), at $\mathrm{pH}$ 9.8. The plate was then incubated in the dark for $45 \mathrm{~min}$ at $37^{\circ} \mathrm{C}$ and then $80 \mu \mathrm{L}$ of a stop solution, $2 \mathrm{M} \mathrm{NaOH}$ (Panreac, Spain) containing 0.2 mM EDTA (Sigma), was added to each well. Standards were prepared with $10 \mu \mathrm{mol} / \mathrm{mol} \mathrm{pNP}$ and the stop solutions in order to achieve the final concentrations ranging between 0 and $0.3 \mu \mathrm{mol} / \mathrm{mol}$. Absorbance was read at $405 \mathrm{~nm}$, and sample concentrations were read off from standard curve graph.

\section{Statistical analysis}

All quantitative experiments were run in triplicate and the results were expressed as mean \pm standard deviation for $n=3$. Statistical analysis of the data was conducted using two-way analysis of variance (ANOVA) with Bonferroni's post hoc comparisons by means of using the GraphPadPrism version 5.0 for Windows (GraphPad Software, USA, http://www.graphpad.com). Differences between the groups with $p<0.05$ were considered to be statistically significant.

\section{Results and discussion}

The preparation of chitin-based biocomposites was achieved through chitin dissolution in [bmim][Ac] and subsequent addition of HA particles. In solution, chitin molecules and HA cannot interact strongly, but the gelation and the high viscosity of the solutions were enough to keep the ceramic particles dispersed uniformly in the polymeric matrices. ILs are known to easily suspend a variety of particles, and the preparation of functionalized cellulose composites, such as films and fibers, via dissolution of cellulose and suspension of functional particulates in the same IL medium has been reported. ${ }^{23}$ Tsioptsias and Panayiotou ${ }^{24}$ made cellulose-nano-HA composite scaffolds based on IL as the dissolution medium. Their study had better results than a procedure using a mixture of dimethylacetamide and $\mathrm{LiCl}$. No phase separation was observed for all of our chitin-based systems, which suggested that the composites were homogeneous. Subsequent extraction with water easily leached the salt particles and also extracted the IL, which is miscible with water.

Although ILs are usually recognized as "green" solvents, they exhibit a certain level of toxicity. ${ }^{25}$ Consequently, IL removal is an important step in the process to obtain a material with minimal toxicity. ${ }^{15,19}$ To remove the IL, the chitin-based structures were submitted to Soxhlet extraction 


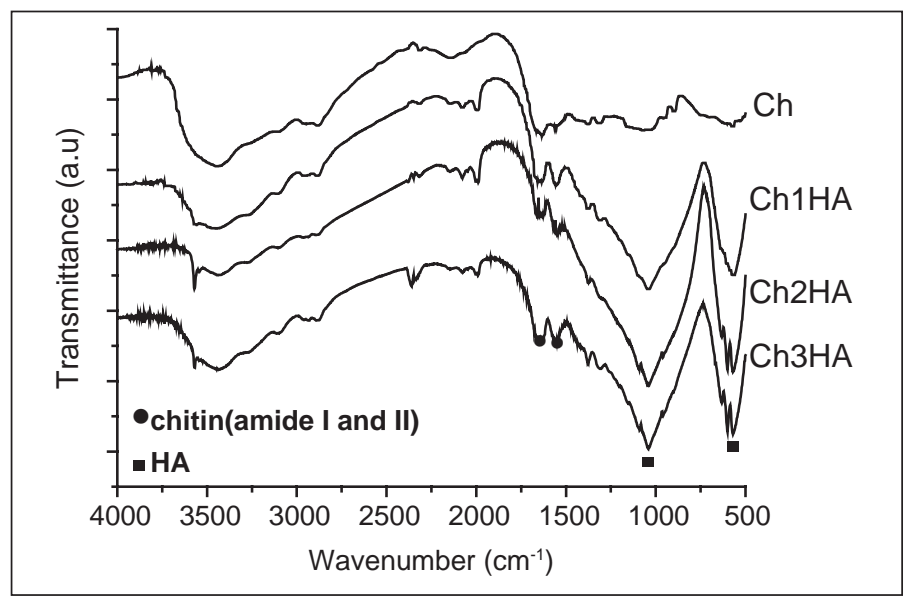

Figure I. FTIR spectra of the chitin-based composite porous materials: $\mathrm{Ch}, \mathrm{ChIHA}, \mathrm{Ch} 2 \mathrm{HA}$, and Ch3HA. FTIR: Fourier transform infrared; HA: hydroxyapatite.

with ethanol and then submitted to a drying process in supercritical fluid drying, where pressure and temperature were maintained constant in order to evaluate the effect of chitin concentration on the final properties of the matrices. In a previous work, ${ }^{15}$ the drying process of the chitin gels was evaluated using air-drying, freeze-drying, and vacuum. The SCF seemed to be superior to all the aforementioned methods for the production of porous chitin structures.

\section{Structural characterization}

The Fourier transform infrared (FTIR) spectra of chitin and ChHA (Figure 1) have typical absorptions for chitin at 1645 and $1560 \mathrm{~cm}^{-1}$ attributed to amide I and amide II groups, respectively. ${ }^{26} \mathrm{By}$ comparing chitin (Figure 1(Ch)) and ChHA (Figure 1(Ch1HA to Ch3HA) spectra, a slight change in the amide I and amide II bands, and intense absorption bands at 569 and $1020 \mathrm{~cm}^{-1}$ were observed, which are attributed to phosphate groups $\left(\mathrm{PO}_{4}{ }^{3-}\right) .{ }^{27}$ These changes clearly indicate the incorporation of HA into chitin structure.

The XRD patterns in Figure 2(a) have a typical $\alpha$-chitin diffraction pattern, with major peaks at $2 \theta=9.44^{\circ} \mathrm{C}, 12.83^{\circ} \mathrm{C}$, and $19.21^{\circ} \mathrm{C}$, corresponding to the (020), (021), and (110) reflection planes, respectively. ${ }^{28}$ Examining the XRD patterns of ChHA (Figure 2(b)), the peaks related to chitin and HA were detected. The XRD patterns in Figure 2(b) of the ChHA composite scaffolds exhibited $2 \theta$ values at $32^{\circ}, 34^{\circ}$, and $39^{\circ}$, which are the characteristics peaks for HA (PDF 9-432). The XRD data were in good agreement with the FTIR where the presence of HA in the chitin matrices was observed. The biocomposite was observed to have an ordered crystalline structure. In a previous study, ${ }^{17}$ a decrease in the crystallinity of chitin matrices obtained from chitin/IL solutions was observed. In fact, the anions, in particular $\mathrm{Ac}^{-}$, can destroy the hydrogen-bonding network of the chitin by interacting with its hydroxyl groups, which decreases the crystallinity of chitin. ${ }^{14}$

\section{Morphology}

The scanning electron microscopy (SEM) images of the ChHA composite structures, in Figure 3, have a heterogeneous porous formation. The variation of polymer concentration associated with 


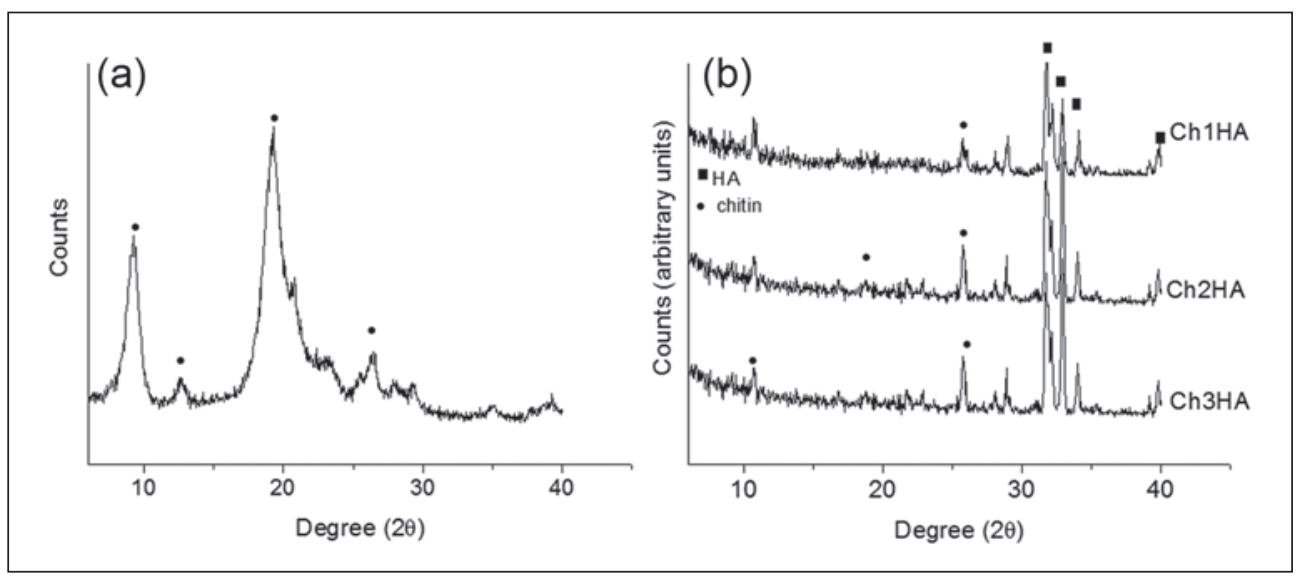

Figure 2. XRD patterns of the chitin-based composite porous materials: (a) Ch and (b) ChIHA, Ch2HA, and $\mathrm{Ch} 3 \mathrm{HA}$.

XRD: X-ray diffraction.

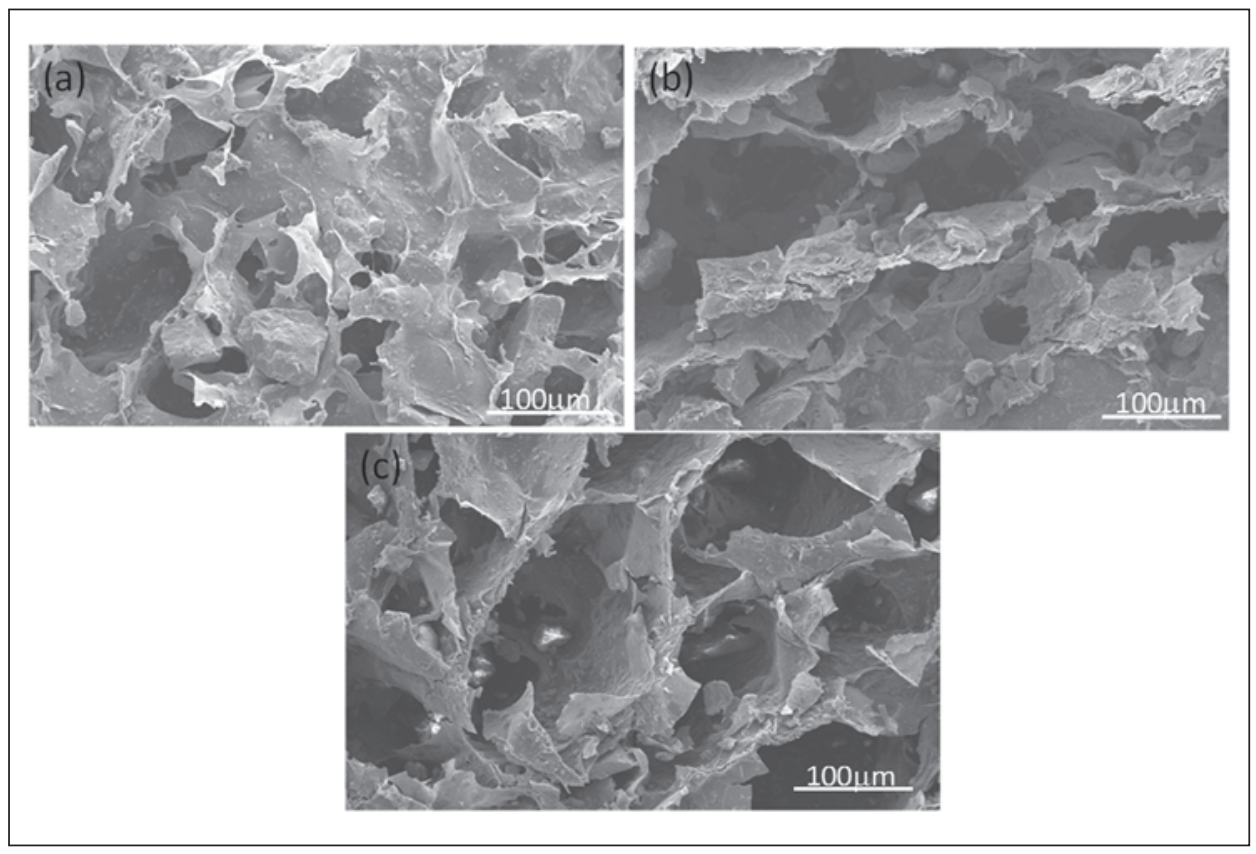

Figure 3. SEM micrographs of cross sections of the chitin-based composite porous materials: (a) ChIHA, (b) $\mathrm{Ch} 2 \mathrm{HA}$, and (c) Ch3HA.

SEM: scanning electron microscopy.

HA incorporation can be the reasons for these morphological features. Some authors ${ }^{29}$ have shown that concentration of polymer and supercritical conditions have a great influence on the final microstructure and degree of interconnectivity of the scaffolds. However, in this study, the supercritical conditions were not varied, whereas polymer concentration was changed. 


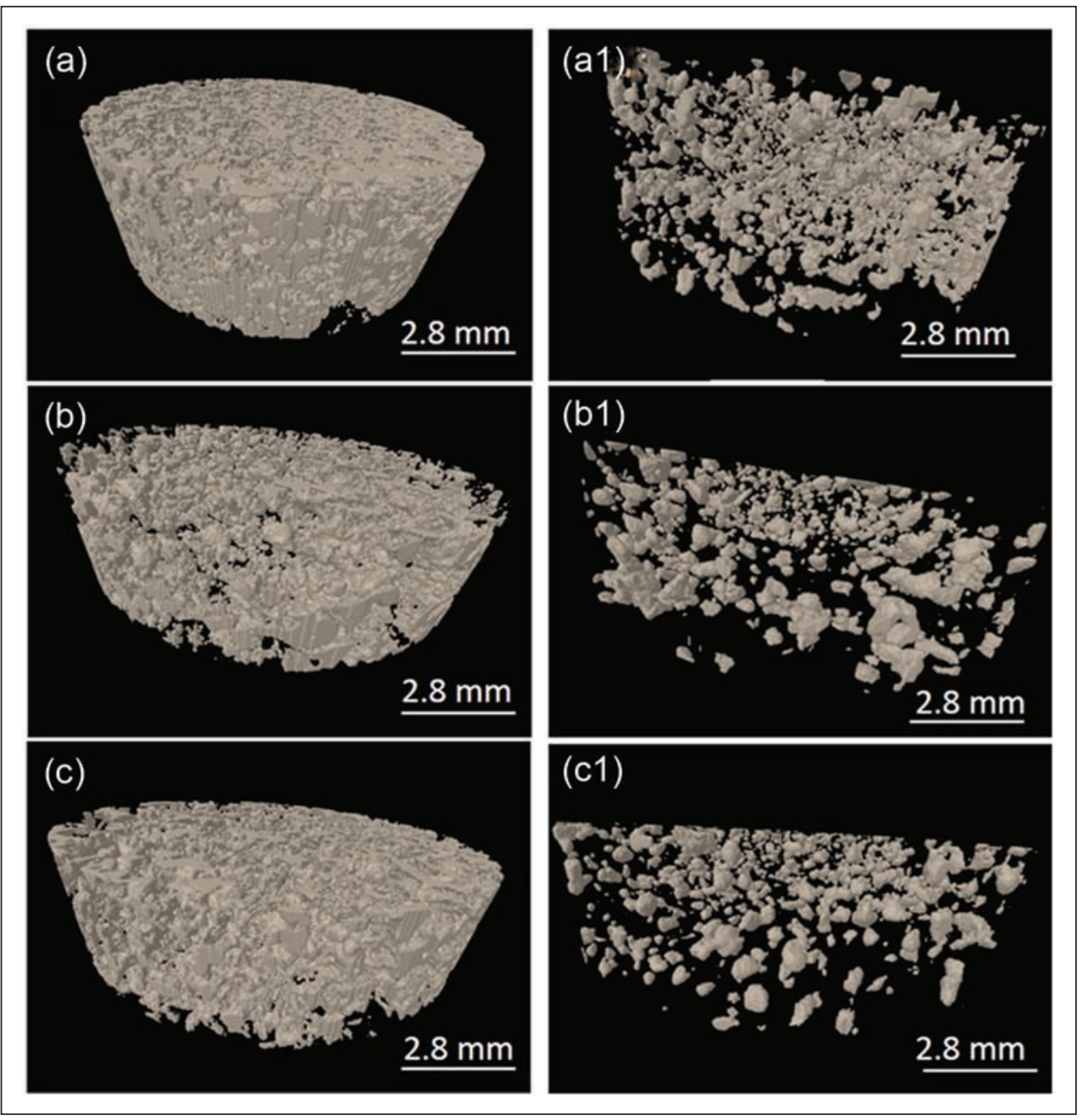

Figure 4. $\mu$-CT images of the chitin-based composite porous structures: (a) ChIHA, (b) Ch2HA, and (c) Ch3HA: (a), (b), and (c) structure complete; (a l), (bl), and (cl) HA only. $\mu$-CT: micro-computed tomography; HA: hydroxyapatite.

$\mu-C T$ analysis was used to obtain quantitative information of the 3D architecture of the chitinbased materials (Figure 4). The higher attenuation coefficient by HA distinguished it within the structure. For all formulations, the HA was homogeneously distributed across the composite structure (Figure 4(a1) to (c1)). Pore size distribution, porosity, and interconnectivity were also quantified. From $\mu$-CT data in Table 1, the HA content in the composite structure was determined. The HA content decreased with increasing polymer concentration. The viscosity of ILs was higher than water but similar to oils, ${ }^{30}$ even though their viscosity decreased with increasing temperature. The chitin-IL solutions were very viscous; the high viscosity of the chitin solution can explain the decrease of HA incorporated (Table 1, Figure 5(d)). The pore size distribution of the samples (Figure 5(a) to (c)) presented values ranging between 50 and $300 \mu \mathrm{m}$. These architectural features could be adequate for tissue engineering purposes. Even though the same salt particles size was used, the structures have different pore size distribution. This could be related to the concentration 
Table I. Microstructural features of the chitin-based composite porous materials, obtained from $\mu-C T$ analysis.

\begin{tabular}{llll}
\hline Sample & Estimated HA content (\%) & Mean 3D porosity (\%) & Interconnectivity (\%) \\
\hline ChIHA & $4.8 \pm 0.5$ & $93.7 \pm 4.5$ & $79.9 \pm 0.1$ \\
Ch2HA & $2.0 \pm 0.3$ & $85.5 \pm 4.0$ & $77.1 \pm 0.4$ \\
Ch3HA & $1.9 \pm 0.1$ & $82.8 \pm 2.3$ & $82.7 \pm 0.3$ \\
\hline
\end{tabular}

$\mu$-CT: micro-computed tomography; HA: hydroxyapatite; 3D: three-dimensional.

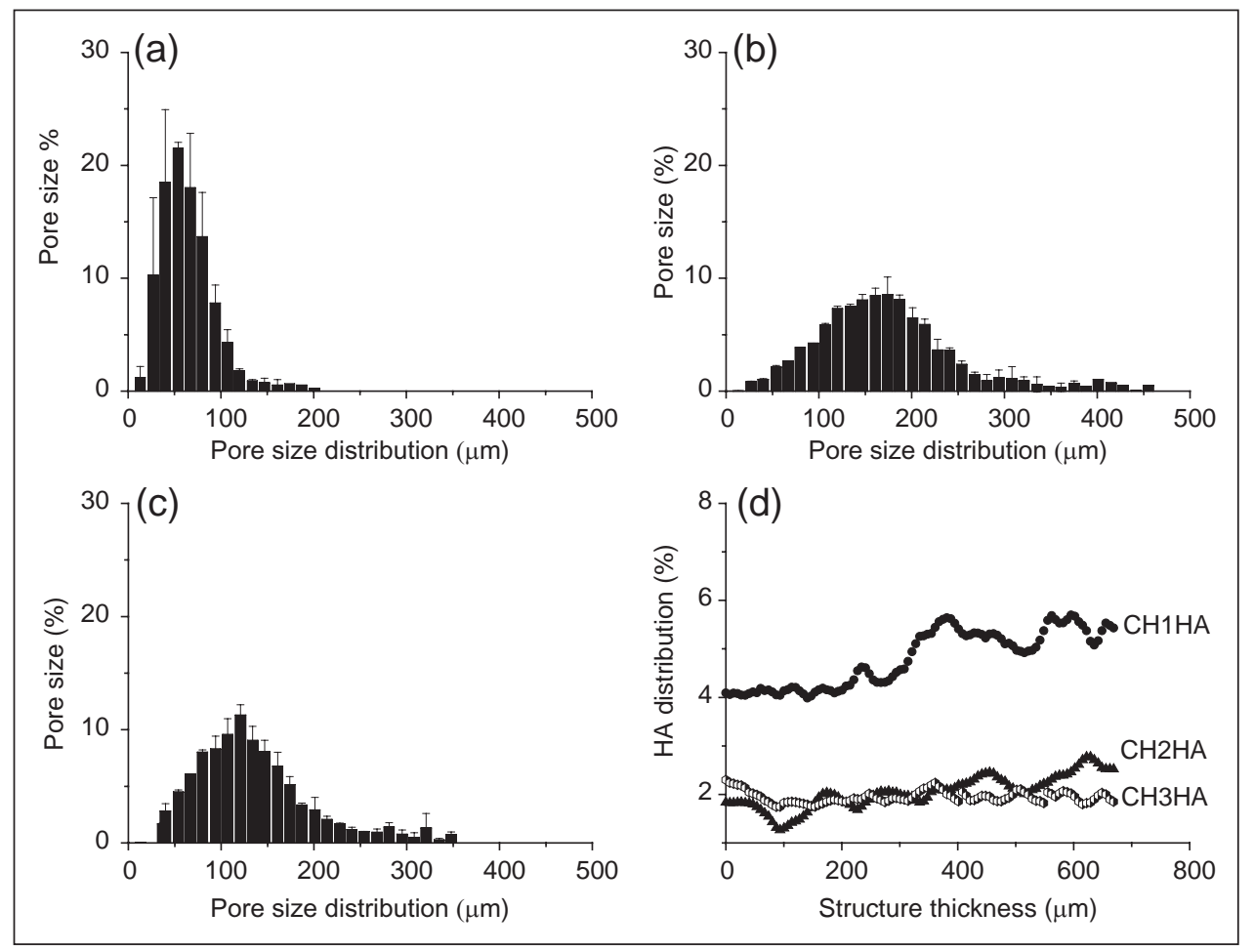

Figure 5. Porosity distribution of chitin-based composite porous structures: (a) ChIHA, (b) Ch2HA, (c) $\mathrm{Ch} 3 \mathrm{HA}$, and (d) HA distribution along the structures.

HA: hydroxyapatite.

of polymer affecting the dispersion of the salt particles in the chitin/IL solutions. Furthermore, the values of interconnectivity of the structures indicated that interconnected pores had formed in all structures, which may help to distribute cells and to transfer nutrients effectively so as to facilitate cell growth within the 3D porous structures. ${ }^{5}$

\section{In vitro cell culture assays}

The possible applications for the ChHA composite porous matrices in bone tissue engineering applications were determined by preliminary in vitro tests using osteoblast-like cells. The cell response of Ch2HA and Ch3HA was assessed as their morphology (Figure 3) was very interesting. 


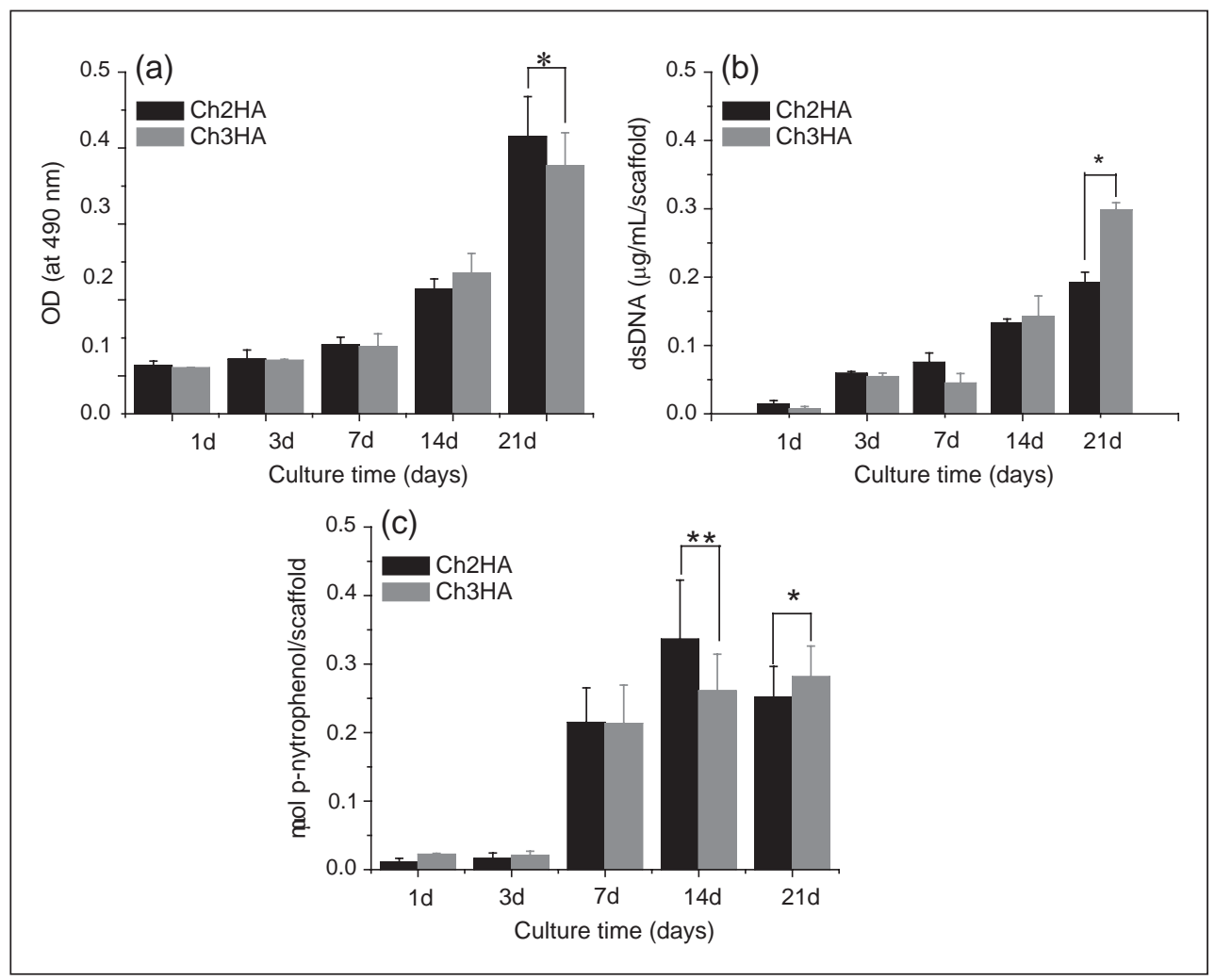

Figure 6. Viability, proliferation, and osteogenesis of the SaOS-2 osteoblast-like cells seeded and cultured onto the chitin-based materials (ChHA2 and ChHA3) after cell seeding at I, 3, 7, I4, and 21 days, by MTS assay (a), DNA content (b), and ALP activity (c). Data represent the mean \pm standard deviation $(n=9$, *p $<$ 0.05 , **p $<0.01$, two-way ANOVA).

ANOVA: analysis of variance; MTS: 3-(4,5-dimethylthiazol-2-yl)-5-(3-carboxymethoxyphenyl)-2-(4-sulfophenyl)-2H-tetra-zolium.

In the MTS assay (Figure 6(a)) the cells remained viable with increasing metabolic rates during all testing periods. The highest viability values were observed for longer time culture periods (14 and 21 days) on both types of structures. Moreover, statistical analysis of the data evidenced significant differences $(p<0.05)$ in the metabolic activity values at 21 days between the two samples. These results indicated that ILs did not cause any deleterious effect on cell viability of the osteoblasts, which in turn suggests efficient [bmim][Ac] removal from the chitin structures. The DNA content of the osteoblast-biocomposite constructs (Figure 6(b)) was measured to quantify the osteoblast growth and proliferation on the materials. An increase in DNA content was observed with the culture time for both biocomposite structures. Nevertheless, a statistical difference $(p<0.05)$ was observed after 21 days of culture between Ch2HA and Ch3HA samples. In addition, the ALP activity was evaluated as an indicator of osteogenic phenotype. An increasing ALP activity (Figure 6(c)) was observed over time for both types of biocomposite materials, whereas Ch2HA showed the highest ALP values at the 14-day time point. Based on the two-way ANOVA statistical analysis of the data, significant differences ( $p<0.05, p<0.01$ ) were found in the ALP values for Ch2HA (14 days) and Ch3HA (21days). Among the formulations tested, the Ch2HA formulation had the largest amount of HA incorporated, as detected by $\mu$-CT analysis (Table 1), which can indicate the role 
of HA in the ALP activity. These results indicated that the developed matrices support the proliferation and the phenotype of SaOs-2 cells.

\section{Conclusion}

An alternative process was developed to prepare composite porous biomaterials by integrating the use of 1-butyl-methylimidazolium acetate as solvent for chitin, followed by the incorporation of HA. The possibility of manipulating the pore size of the structures was evaluated using different chitin concentrations in combination with salt leaching and supercritical fluid drying. These chitin/HA composites exhibited good distribution of HA particles in the chitin matrix, heterogeneous porous formation, high porosity, and interconnectivity. In addition, the properties of these chitin-based composite biomaterials were dependent on the polymer concentration. The in vitro biological analysis revealed a positive influence on the viability and proliferation of osteoblast-like cells. It was shown in this study that the dissolution of chitin in ILs, particularly in [bmim][Ac], can be used in the processing of composite porous biomaterials suitable for bone tissue engineering purposes.

\section{Declaration of conflicting interests}

The authors declare that there is no conflict of interest.

\section{Funding}

Simone S. Silva and Miguel Oliveira received financial support from the Portuguese Foundation for Science and Technology-FCT (Grant SFRH/BPD/45307/2008 and SFRH/BPD/21786/2009, respectively), "Fundo Social Europeu”-FSE, and "Programa Diferencial de Potencial Humano-POPH.” This work was partially supported by the FEDER through POCTEP 0330_IBEROMARE_1_P and European Union Seventh Framework Programme (FP7/2007-2013) under grant agreement no. KBBE-2010-266033 (project SPECIAL).

\section{References}

1. Rinaudo M. Chitin and chitosan: properties and applications. Prog Polym Sci 2006; 31: 603-632.

2. Sashiwa $\mathrm{H}$ and Aiba S-i. Chemically modified chitin and chitosan as biomaterials. Prog Polym Sci 2004; 29: 887-908.

3. Silva SS, Mano JF and Reis RL. Potential applications of natural origin polymer-based systems in soft tissue regeneration. Crit Rev Biotechnol 2010; 30: 200-221.

4. Chow KS and Khor E. Novel fabrication of openpore chitin matrixes. Biomacromolecules 2000; 1: 61-67.

5. Madihally SV and Matthew HWT. Porous chitosan scaffolds for tissue engineering. Biomaterials 1999; 20: $1133-1142$.

6. Swetha M, Sahithi K, Moorthi A, et al. Biocomposites containing natural polymers and hydroxyapatite for bone tissue engineering. Int J Biol Macromol 2010; 47: 1-4.

7. Weng $\mathrm{J}$ and Wang $\mathrm{M}$. Producing chitin scaffolds with controlled pore size and interconnectivity for tissue engineering. J Mater Sci Lett 2001; 20: 1401-1403.
8. ZhuC,FanD, MaX, etal.Effects of chitosanonproperties of novel human-like collagen/chitosan hybrid vascular scaffold. J Bioact Compat Polym 2009; 24: 560-576.

9. Oliveira JM, Rodrigues MT, Silva SS, et al. Novel hydroxyapatite/chitosan bilayered scaffold for osteochondral tissue-engineering applications: scaffold design and its performance when seeded with goat bone marrow stromal cells. Biomaterials 2006; 27: 6123-6137.

10. Oliveira JM, Silva SS, Mano JF, et al. Innovative technique for the preparation of porous bilayer hydroxyapatite/chitosan scaffolds for osteochondral applications. Bioceramics 2006; 18: 927-930.

11. Ma X, Wang Y, Guo H, et al. Nano-hydroxyapatite/ chitosan sponge-like biocomposite for repairing of rat calvarial critical-sized bone defect. J Bioact Compat Polym 2011; 26: 335-346.

12. Holbrey JD and Rogers RD. Physicochemical properties of ionic liquids. In: Wasserscheid $\mathrm{P}$ and Welton T (eds) Ionic liquids in synthesis. Weinheim: Wiley-VCH Verlag GmbH \& Co., 2002, p. 57.

13. Mine S, Izawa H, Kaneko $\mathrm{Y}$, et al. Acetylation of $\alpha$-chitin in ionic liquids. Carbohydr Res 2009; 344: 2263-2265. 
14. Wu Y, Sasaki T, Irie S, et al. A novel biomass-ionic liquid platform for the utilization of native chitin. Polymer 2008; 49: 2321-2327.

15. Silva SS, Duarte ARC, Carvalho AP, et al. Green processing of porous chitin structures for biomedical applications combining ionic liquids and supercritical fluid technology. Acta Biomater 2011; 7: 1166-1172.

16. Qin Y, Lu XM, Sun N, et al. Dissolution or extraction of crustacean shells using ionic liquids to obtain high molecular weight purified chitin and direct production of chitin films and fibers. Green Chem 2010; 12: 968-971.

17. Wang W-T, Zhu J, Wang X-L, et al. Dissolution behavior of chitin in ionic liquids. J Macromol Sci B 2010; 49: 528-541.

18. Xie H, Zhang $\mathrm{S}$ and $\mathrm{Li}$ S. Chitin and chitosan dissolved in ionic liquids as reversible sorbents of $\mathrm{CO}_{2}$. Green Chem 2006; 8: 630-633.

19. Silva SS, Santos TC, Cerqueira MT, et al. The use of ionic liquids in the processing of chitosan/silk hydrogels for biomedical applications. Green Chem 2012; 14: 1463-1470.

20. Sescousse R, Gavillon R and Budtova T. Aerocellulose from cellulose-ionic liquid solutions: preparation, properties and comparison with cellulose- $\mathrm{NaOH}$ and celluloseNMMO routes. Carbohydr Polym 2011; 83: 1766-1774.

21. Song H, Zhang J, Niu Y, et al. Phase transition and rheological behaviors of concentrated cellulose/ ionic liquid solutions. J Phys Chem C 2010; 114: 6006-6013.
22. Zhang Z and Zhao ZK. Solid acid and microwaveassisted hydrolysis of cellulose in ionic liquid. Carbohydr Res 2009; 344: 2069-2072.

23. Sun N, Rodriguez H, Rahman M, et al. Where are ionic liquid strategies most suited in the pursuit of chemicals and energy from lignocellulosic biomass? Chem Commun 2011; 47: 1405-1421.

24. Tsioptsias C and Panayiotou C. Preparation of cellulose-nanohydroxyapatite composite scaffolds from ionic liquid solutions. Carbohydr Polym 2008; 74: 99-105.

25. Zhao D, Liao Y and Zhang Z. Toxicity of ionic liquids. Clean 2007; 35: 42-48.

26. Cárdenas G, Cabrera G, Taboada E, et al. Chitin characterization by SEM, FTIR, XRD, and 13C cross polarization/mass angle spinning NMR. J Appl Polym Sci 2004; 93: 1876-1885.

27. Raynaud S, Champion E, Lafon JP, et al. Calcium phosphate apatites with variable $\mathrm{Ca} / \mathrm{P}$ atomic ratio III. Mechanical properties and degradation in solution of hot pressed ceramics. Biomaterials 2002; 23: 1081-1089.

28. Zia KM, Bhatti IA, Barikani M, et al. XRD studies of polyurethane elastomers based on chitin/1,4-butane diol blends. Carbohydr Polym 2009; 76: 183-187.

29. Duarte ARC, Mano JF and Reis RL. Preparation of chitosan scaffolds loaded with dexamethasone for tissue engineering applications using supercritical fluid technology. Eur Polym J 2009; 45: 141-148.

30. Pinkert A, Marsh KN, Pang S, et al. Ionic liquids and their interaction with cellulose. Chem Rev 2009; 109: 6712-6728. 